\title{
Comparing the innovation performance in Canadian, French and German manufacturing enterprises
}

Citation for published version (APA):

Mohnen, P., \& Therrien, P. (2005). Comparing the innovation performance in Canadian, French and German manufacturing enterprises. UNU-MERIT, Maastricht Economic and Social Research and Training Centre on Innovation and Technology. MERIT-Infonomics Research Memorandum Series No. 028 https://doi.org/10.26481/umamer.2005028

Document status and date:

Published: 01/01/2005

DOI:

10.26481/umamer.2005028

Document Version:

Publisher's PDF, also known as Version of record

\section{Please check the document version of this publication:}

- A submitted manuscript is the version of the article upon submission and before peer-review. There can be important differences between the submitted version and the official published version of record.

People interested in the research are advised to contact the author for the final version of the publication, or visit the DOI to the publisher's website.

- The final author version and the galley proof are versions of the publication after peer review.

- The final published version features the final layout of the paper including the volume, issue and page numbers.

Link to publication

\footnotetext{
General rights rights.

- You may freely distribute the URL identifying the publication in the public portal. please follow below link for the End User Agreement:

www.umlib.nl/taverne-license

Take down policy

If you believe that this document breaches copyright please contact us at:

repository@maastrichtuniversity.nl

providing details and we will investigate your claim.
}

Copyright and moral rights for the publications made accessible in the public portal are retained by the authors and/or other copyright owners and it is a condition of accessing publications that users recognise and abide by the legal requirements associated with these

- Users may download and print one copy of any publication from the public portal for the purpose of private study or research.

- You may not further distribute the material or use it for any profit-making activity or commercial gain

If the publication is distributed under the terms of Article $25 \mathrm{fa}$ of the Dutch Copyright Act, indicated by the "Taverne" license above, 


\section{MERIT-Infonomics Research Memorandum series}

Comparing the Innovation Performance in Canadian, French and German Manufacturing Enterprises

\section{Pierre Mohnen \& Pierre Therrien}

\section{$2005-028$}



MERIT - Maastricht Economic Research Institute on Innovation and Technology

PO Box 616

6200 MD Maastricht

The Netherlands

T: +31433883875

F: +31 433884905

http://www.merit.unimaas.nl

e-mail:secr-merit@merit.unimaas.nl

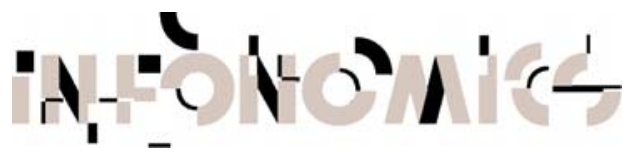

International Institute of Infonomics

c/o Maastricht University

PO Box 616

6200 MD Maastricht

The Netherlands

T: +31 433883875

F: +31 453884905

http://www.infonomics.nl

e-mail: secr@infonomics.nl 


\title{
Comparing the Innovation Performance in Canadian, French and German Manufacturing Enterprises
}

\author{
Pierre Mohnen* \\ and \\ Pierre Therrien **
}

September 2005

* University of Maastricht, MERIT and CIRANO

** Industry Canada

We would like to thank Brian Nemes, Frances Anderson and Susan Schaan for guiding us through Statistics Canada's 1999 Survey of Innovation and Frank Foyn and Dominique Guellec for helping us with the European CIS 2 surveys. The first author also acknowledges financial support from SSHRC.

\begin{abstract}
This paper compares pairwise the innovation performance of Canada with France and Germany, respectively. The comparison is based on two ordered probit models with sample selection, one where innovation is measured by the introduction of new-to-the firm products and one where it is measured by the introduction of new-to-the market products. The econometric analysis attempts to explain part of the country differences as the result of the sectoral composition of output, and the effects of size, environment conditions (proximity to basic research and competition) and innovation activities (internal R\&D, the number of innovation activities, cooperation and government support). The Canadian firms benefit from being larger and more numerous in receiving government support, but suffer from a lack of competition and internal R\&D. These structural effects combined, while informative, are not enough to explain a lot of the basic pattern of innovation revealed by the raw data. If we take the stronger measure of firstto-market innovation as a yardstick of innovation, the observed pairwise country differences are less strong, and our model explains a little bit more of the observed differences.
\end{abstract}

JEL codes: O31, O51, O52 


\section{Introduction}

In two previous papers we set the stage to compare Canada's innovation performance with that of four European countries (France, Germany, Ireland and Spain) using the microdata information from Canada's 1999 Innovation Survey and Eurostat's second wave of Community Innovation Surveys (CIS 2). In Therrien and Mohnen (2003) we assessed the comparability of the Canadian and European innovation surveys and we discussed some appropriate transformations that would enable to compare the respective innovation survey data. In Mohnen and Therrien (2003) we compared innovation in Canada and the four European countries as a whole. The results showed that, on the basis of the innovation surveys, Canada had a higher proportion of innovating firms but a lower share of innovative sales for their innovating firms. Combining these two factors (probability to innovate and intensity of innovation), the expected intensity of innovation was slightly higher for Canada than for Europe. Using the innovation accounting framework developed in Mairesse and Mohnen (2001), we found that Canadian manufacturing firms were advantaged by their size and their tendency to co-operate with other firms, while the European firms benefited from the sectoral composition of their manufacturing output, the competitive pressure, and the novelty of innovation.

Given the nature of innovation, it is likely that a single innovation indicator will not account for all the complexity. We have to look at various innovation indicators. The innovation surveys actually distinguish two kinds of innovators: the new-to-firm innovators, who introduce products new to them but that already existed on the market, and the first-to-market innovators, who introduce products new to the market. ${ }^{1}$ A few studies have differentiated the two types of innovations: Brouwer and Kleinknecht (1996) for the Netherlands, Duguet (2002) for France, Lööf et al. (2003) for Finland, Norway and Sweden, and Baldwin and Hanel (2003), Cozzarin (2003), Landry and Amara (2003), and Therrien and Chang (2003) for Canada.

We shall build on our previous two papers but deviate from them in two respects. First, we reconsider the Canadian comparison with respect to Europe by differentiating between new-tothe-firm innovators, which henceforth we shall call simple innovators, and new-to-the-market innovators. In both cases, we estimate the determinants of the respective innovations and compare the countries' innovation performance on the basis of differences in the magnitude or the frequency of occurrence of these determinants. Do the two indicators lead to a different evaluation of Canada's comparative innovation performance? Secondly, instead of comparing the innovation performances between two blocs of countries, we here perform bilateral comparions between Canada and France, on the one hand, and between Canada and Germany, on the other. In doing so, we let each country have its own innovation structure. There are few cross-country comparisons using microlevel innovation survey data, partly because of the confidential nature of the data, partly because of differences in the structure of the surveys. Mairesse and Mohnen (2001) and Mohnen and Dagenais (2002) compare the innovation performance of seven European countries using pooled micro-aggregated data from CIS 1. Lööf et al. (2003) compare the innovation performance of Finland, Norway and Sweden using CIS 2 data and estimating separately the data from each country. Janz et al. (2003) compare the

\footnotetext{
${ }^{1}$ Brouwer and Kleinknecht (1996) call the former imitative innovators and the latter true innovators.
} 
innovation performance of German and Swedish firms by estimating separately and by pooling the respective CIS 3 data. Mohnen and Therrien (2003) compare the CIS 2 data of four European countries and the Canadian 1999 innovation survey, estimating separately the Canadian data and the pooled micro-aggregated European data. Griffith, Huergo, Mairesse and Peters (2005) and Abramovsky, Jaumandreu, Kremp and Peters (2005) compare innovation in Germany, France, Spain and the United Kingdom by estimating the same model using individual country level CIS2 data.

We proceed as follows. Since what can be compared depends very much on the data at hand, we first present the data, the conditions under which they are comparable, and we give some descriptive statistics about the comparative innovation performance and characteristics of innovators in the three countries. In section 3, we present the econometric model that underlies our analysis of the explanation of country differences. In section 4, we interpret the econometric results. In section 5, we conclude by summarizing the main results and by suggesting some future improvements.

\section{Data $^{2}$}

The comparison of the innovation performance of manufacturing firms in Canada, France and Germany is based on two separate databases. The Canadian data come from Statistics Canada's 1999 Survey of Innovation, while the French and German data came from CIS 2, the second wave of European Community Innovation Surveys. Both surveys follow the guidelines set out in the Oslo Manual (OECD/Eurostat, 1997). They use the same definitions of innovation and contain common questions regarding the innovation process (e.g. obstacles to innovation, activities related to innovation, objectives of innovation) and its outcomes. However, despite all efforts made to make the surveys as similar as possible, there are some subtle differences between the Canadian and the European surveys. Some of them are easy to overcome (see Therrien and Mohnen, 2003), others not.

The first discrepancy concerns the definition of the statistical unit. It is the enterprise in the European survey and the notion of "provincial enterprise" in the Canadian survey. ${ }^{3}$ After conducting some data analysis, we concluded that using the provincial enterprise rather than the enterprise as the statistical unit does not seem to lead to any serious bias. The second discrepancy pertains to the years covered by the surveys: 1997-1999 for Canada and 1994-1996 for Europe. The later period may have favoured the small provincial enterprises in Canada and those in the low-tech industries. ${ }^{4}$ These firms had a higher innovation rate than their European

\footnotetext{
${ }^{2}$ For a complete description and comparison of CIS 2 and Statistics Canada's 1999 Survey of Innovation, and the tests performed and assumptions made to harmonize the two databases, see Therrien and Mohnen (2003). For official reports regarding the surveys, see Schaan and Nemes (2003) for Canada and Foyn $(1999,2000)$ for Europe.

${ }^{3}$ A "provincial enterprise" includes all establishments of a given enterprise in the same province and industry at the four-digit NAICS level. According to this definition, a firm can be represented more than once in the sample.

${ }^{4}$ Therrien and Mohnen (2003) reported that $77 \%$ of Canadian firms in the low-tech sector were innovative compared with $41 \%$ of European firms (taking a weighted average of the observations from France, Germany,
} 
counterparts, although this was no longer the case if novelty was restricted to the stronger definition of first-to-market innovation. The third discrepancy has to do with the data themselves: we have only access to microaggregated data for the four European countries but to raw micro-data at the level of the provincial enterprise for Canada. However, Mairesse and Mohnen (2001) showed that, for an econometric model similar to the one used in the study reported here, the microaggregated nature of the data has little bearing on the results.

The core question asked in the innovation surveys is whether new or significantly improved products or processes had been introduced during the three-year period of reference (1994-96 and 1997-99 for Europe and Canada, respectively). Firms that indicated that they had introduced an innovation (be it a product or a process) were asked to fill out the rest of the questionnaire. The variable that is particularly interesting for the purpose of comparing the innovation performance of firms in different countries, and that is unique to the innovation surveys, is the share of sales resulting from innovative products. It is an output measure of innovation and can be regarded as the sales value weighted average of the number of innovations. The share of innovative sales increases as the number of innovations increases and they are highly valued on the market. In Canada, only product innovators (which include product and process innovators and product innovators only, but exclude process innovators only) were asked to answer this question. Also in Canada, the respondents were given a choice of six size categories $(1-5 \%, 6-$ $15 \%, 16-25 \%, 26-50 \%, 51-75 \%$ and $76-100 \%$ ) of percentages of sales from new or significantly improved products, while in Europe no such categories were defined. To harmonize this variable in Canada and Europe, two steps were taken. First, all innovators that were process innovators only - identified as those who declare themselves to be process innovators but report no sales of innovative products - were excluded from the European sample. Second, the European observations on the shares of innovative sales were regrouped into the same categories as those defined in the Canadian survey.

To distinguish between innovators and first-to-market innovators, that is between a fairly large definition of innovation and a more restricted one, the Canadian innovation survey asks firms to describe their most important innovation and then to indicate whether it was a world-first innovation, a first in Canada, and a first to the firm. The European surveys distinguish products new to the firm and products new to the firm's market. For the sake of comparability, we define a first-to-market innovator as a firm that has introduced a product new to the firm's market for European data and a Canada-first or a world-first innovation for Canadian data. Sales from product innovation can then be calculated for innovators and first-to-market innovators, respectively. ${ }^{5}$ Unfortunately, the Canadian questionnaire does not, unlike the European one, ask for the share of sales due to products new to the market.

Both surveys provide data on a set of variables that could explain the share of sales due to innovative products. For the present study, firm size is measured by the number of employees (expressed in logarithms). Industries are divided into three groups according to their

Ireland and Spain). Similarly, 75\% of small firms in Canada reported an innovation compared with $42 \%$ in Europe. In contrast, $88 \%$ of large Canadian firms were innovative compared with $82 \%$ of large European firms.

5 Strictly speaking, in Canada only those firms that described their major innovation had to indicate whether it was a world-first or Canada-first. Innovations other than the major one were not relevant for this question. The incidence of first-to-market innovations is therefore likely to be underestimated. 
technological intensity (see the Appendix). A dummy variable indicates the incidence of internal R\&D. ${ }^{6}$ Information is also available on the number of pursued innovation activities. For Canada, these innovation activities are $\mathrm{R} \& \mathrm{D}$, acquisition of machinery and equipment, industrial engineering and industrial design, tooling up and training related to innovation. The European survey, in addition, divides R\&D into internal and external R\&D and includes the activity of introducing innovations to the market. The number of innovation activities is considered to be an indicator of innovation efforts. Firms with more than the median number of innovation activities are separated out from those with less than the median number of activities. The use of some kind of government support for innovation, and involvement in co-operation or collaboration with other firms are taken directly from the dataset. Finally, a measure of proximity to basic research and a measure of competitive pressure, both of which are expected to foster innovation, are constructed. The former is constructed as a dummy, set to 1 if the respondent used universities or government laboratories as a source of information for innovation (Canada), or gave a score greater than the median score on a Likert scale to the use of universities or government laboratories as a source of information for innovation (Europe). For Europe, only national universities and national government laboratories are taken into account, while for Canada no such distinction is made. The variable competitive pressure is constructed as a dummy with value 1 if the objective of "opening up new markets or increasing market share" was given a score above the median. For Canada, the same procedure is applied to the success factor "seeking new markets."

The original data sets were cleaned to remove outliers and to harmonize the Canadian and European data. To obtain comparable data, all firms with a gross business income of less than $€ 165,000$ (or C\$250,000) or fewer than 20 employees, and all those from the printing and publishing industry were removed. ${ }^{7}$ For the European data, missing values for the criterion defining innovators (i.e., firms that had introduced a new product or process) were replaced by zeros - in other words, these firms were treated as non-innovators - and missing values for the share of sales from innovative products were also replaced by zeros (with the possible elimination of these firms if they declared themselves to be process innovators). Missing values for the dummies underlying the measures of proximity to basic research, competitive pressure and co-operation were assigned a value of zero. All firms for which the logarithm of labour productivity was located outside the interval defined by the country mean plus or minus four times the country standard error were excluded. Finally, for Europe, firms with $\mathrm{R} \& \mathrm{D} / \mathrm{sales}$ or R\&D personnel/total personnel above $50 \%$, which could represent research units, were also excluded. That leaves 4,404 observations for Canada, 4,434 for France, and 1,537 for Germany. Raising factors are applied to the sample data so as to cover the total population.

Table 1 shows selected descriptive statistics for innovators and first-to-market innovators, by country. Compared to France, Canada has a higher rate of innovation and a higher share of

\footnotetext{
${ }^{6}$ For Canada, the dummy is set to 1 if a firm carried out R\&D internally in a separate and distinct R\&D department or if it performed R\&D without contracting it out to other firms.

${ }^{7}$ The publishing industry is classified differently according to the European industry classification (NACE) or the Canadian industry classification (NAICS). The NAICS classifies the publishing industry outside the manufacturing sector, but the NACE classifies it as a subgroup of printing industries in the manufacturing sector. Because publishing activities constitute an important share of the printing industry, the whole Printing and Related Support Activities industry (NAICS 323 and NACE 22) was excluded.
} 
innovation sales, for both innovators and first-to-market innovators, although the difference is substantially lower when we consider first-to-market innovations. Compared to Germany, Canada still leads in the rate of innovation, but Germany has a higher incidence of first-tomarket innovators and significantly higher shares of innovative sales for both innovators and first-to-market innovators.

Innovators and first-to-market innovators are similarly distributed across the three industry groupings in the three countries: the bulk of innovators are in the medium-tech sectors, $20 \%$ to $30 \%$ belong to the low-tech sectors and between $12 \%$ and $20 \%$ belong to the high-tech sectors. The percentage of first- to-market innovators is always higher than the percentage of simple innovators in the high-tech and medium-tech sectors, reflecting probably the higher technological opportunities that exist in these sectors. It is also worthwhile to notice that France has, of all three, the highest percentage of high-tech innovators, Germany the largest fraction of medium-tech innovators, whereas Canada specializes in low-tech innovations. First-to-market innovators are, on average, larger than innovators in all three countries. France is the country where the difference in size is the lowest between innovators and first-to-market innovators (average size of 86 and 96 employees, respectively).

The percentage of firms involved in activities linked to innovation (internal $\mathrm{R} \& \mathrm{D}$, multiple innovation activities, co-operation, and government programs) is always higher for first-tomarket innovators than for simple innovators. Notice that first-to-market innovators from Germany are the most involved in multiple innovation activities $(85 \%)$ and have the highest incidence of internal R\&D (90\%). Collaborations in innovation are more frequent in France and Canada than in Germany. First-to-market innovators tend to cooperate more than simple innovators. Canadian innovators benefit substantially more from government support programs (64\% for simple innovators and $75 \%$ for first-to-market innovators). We would expect proximity to basic research to characterize first-to-market innovators more than simple innovators, and yet the percentage for first-to-market innovators is substantially lower in Germany. Finally, in the three countries, the pressure from competition is more severely felt by first-to-market innovators than by simple innovators .

\section{Model}

To compare the innovation performance of manufacturing firms in Canada, France and Germany we rely on three innovation output indicators: the proportion of innovating firms, that is firms that declare having introduced a new product or a new process in the preceding three years, the proportion of first-to-market innovators, i.e. those who have introduced a product new to the market, and for each category the share in total sales due to innovative products, that is to say new or substantially improved products. Our goal is to go beyond the mere reporting of comparative statistics and to try and explain why innovation performances differ in the three dimensions. In determining the appropriate econometric model to handle these data, four remarks have to be made regarding the structure of the data. 
First, the way in which the survey questionnaire is set up raises a censoring problem. Before the question on the percentage of sales resulting from innovative products, there is a filtering question requiring firms to declare whether they have introduced a new product or a new process in the previous three years. If they answer "no" to both questions, then they have to provide only a minimal amount of information, essentially their size (in terms of turnover and employment) and their main sector of activity. If they answer "yes" to either of the questions, they declare themselves to be innovative and only then are they invited to respond to another set of questions regarding the inputs, the outputs and the organization of their innovations. Second, some firms identify themselves as innovative but report no innovative sales. Either these firms do only process innovations or they are innovative but have not yet been able to introduce their product on the market. All pure process innovators were eliminated, and the European product innovators with no sales from innovative products were put in the category of innovators with less than $5 \%$ of sales from innovative products. Third, as mentioned before, the data on the percentage of sales from innovative products are categorical and not continuous, because the Canadian questionnaire reports only categorical data. Fourth, for first-to-market innovators we only have the share of total innovative sales, i.e. of products new to the firm or to the market, not the specific share of innovative sales due to products new to the market.

Given the structure of the data, the natural choice of modeling is a probit model distinguishing between innovative and non-innovative firms, followed by and linked to a multinomial ordered probit model (with known bounds) determining the importance of sales from innovative products. The econometric model is thus as follows. To simplify notation, the enterprise index is omitted.

$I N N O$ denotes the binary variable of whether a firm innovates or not and INNO* the underlying latent variable, such that

$$
\begin{array}{lll}
I N N O=1 & \text { if } & I N N O^{*}=X \beta+\varepsilon \geq 0 \\
I N N O=0 & \text { if } & I N N O^{*}=X \beta+\varepsilon<0
\end{array}
$$

where $X$ is a matrix of explanatory variables, $\beta$ represents the coefficients to be estimated and $\varepsilon$ is a random error term with mean zero and unit variance. ${ }^{8} \mathrm{~A}$ negative value for $I N N O^{*}$ is associated with a zero response to $I N N O$, and a positive value for $I N N O^{*}$ is associated with a unity response to INNO. INNO* is like the threshold beyond which it is worth innovating.

$I N N O \_S$ denotes the share of sales from innovative products. To the observed ordered responses to the variable $I N N O \_S$ is associated a latent variable

$$
Z I N N S_{-} S^{*}=\ln \left(\mathrm{INNO} \_\mathrm{S} /\left(1-\mathrm{INNO} \_\mathrm{S}\right)\right)=Z \gamma+\sigma_{\eta} \eta
$$

where $Z$ is a matrix of explanatory variables, $\gamma$ represents the corresponding coefficients to be estimated and $\eta$ is a random error term with mean zero and variance 1 . The ordered responses to $I N N O \_S$ correspond to defined intervals of realization of the latent variable:

\footnotetext{
${ }^{8}$ As the variance of $\varepsilon$ is not identifiable, it is set as equal to 1 .
} 


$$
\begin{array}{cl}
I N N O_{-} S=1 & \text { if } I N N O^{*}=0 \text { and } 0 \%<I N N O_{-} S^{*} \leq 5 \% \text { or }-\infty<Z I N N O_{-} S^{*} \leq-2.94 \\
I N N O_{-} S=2 & \text { if } I N N O^{*}=0 \text { and } 5 \%<I N N O_{-} S^{*} \leq 15 \% \text { or }-2.94<Z I N N O_{-} S^{*} \leq-1.73 \\
I N N O_{-} S=3 & \text { if } I N N O^{*}=0 \text { and } 15 \%<I N N O_{-} S^{*} \leq 25 \% \text { or }-1.73<Z I N N O_{-} S^{*} \leq-1.10 \\
I N N O_{-} S=4 & \text { if } I N N O^{*}=0 \text { and } 25 \%<I N N O_{-} S^{*} \leq 50 \% \text { or }-1.10<Z I N N O_{-} S^{*} \leq 0 \\
I N N O_{-} S=5 & \text { if } I N N O^{*}=0 \text { and } 50 \%<I N N O_{-} S^{*} \leq 75 \% \text { or } 0<Z I N N O_{-} S^{*} \leq 1.90 \\
I N N O_{-} S=6 & \text { if } I N N O^{*}=0 \text { and } \quad I N N O_{-} S^{*}>75 \% \text { or } 1.90<Z I N N O_{-} S^{*} \leq \infty
\end{array}
$$

$\varepsilon$ and $\eta$ are assumed to be independently and identically distributed according to a standard bivariate normal distribution $\mathrm{g}(\varepsilon, \eta)$ with correlation coefficient $\rho$. The logit transformation of the latent variable $I N N O \_S^{*}$ into $Z I N N O \_S^{*}=\ln \left(I N N O \_S^{*} /\left(1-I N N O \_S^{*}\right)\right)$ stretches its domain of definition from $[0,1]$ to $[-\infty,+\infty]$. The thresholds defining the categories $t_{i}(i=1, \ldots, 5)$ are transformed accordingly: e.g., $\mathrm{t}_{\mathrm{i}}=0.05$ becomes $t_{i}^{\prime}=\ln (0.05 / 0.95)=-2.94$. The $\beta, \gamma$ and $\rho$ parameters are estimated by maximum likelihood — i.e., the likelihood of observing the $0 / 1$ responses to INNO and the categorical responses to $I N N O \_S$ that were observed for innovators is maximized. The log-likelihood function is given by

$$
\begin{aligned}
& \ln L=\sum_{I N N O_{=0}} \ln \left(\int_{-\infty}^{-X \beta} \int_{-\infty}^{-\infty} g(\varepsilon, \eta) d \varepsilon d \eta+\right. \\
& \sum_{I N N O=1, I N N O_{-} S=1} \ln \left(\int_{-X \beta}^{\infty} \int_{-\infty}^{t_{1}^{*}-Z \gamma^{*}} g(\varepsilon, \eta) d \varepsilon d \eta\right)+ \\
& \sum_{I N N O=1, I N N O_{-} S=2} \ln \left(\int_{-X \beta}^{\infty} \int_{t_{1}^{*}-Z \gamma^{*}}^{t_{2}^{*}-Z \gamma^{*}} g(\varepsilon, \eta) d \varepsilon d \eta\right)+ \\
& \sum_{I N N O=1, I N N O_{-} S=3} \ln \left(\int_{-X \beta}^{\infty} \int_{t_{2}^{*}-Z \gamma^{*}}^{t_{3}^{*}-Z \gamma^{*}} g(\varepsilon, \eta) d \varepsilon d \eta\right)+ \\
& \sum_{I N N O=1, I N N O_{-} S=4} \ln \left(\int_{-X \beta}^{\infty} \int_{t_{3}^{*}-Z \gamma^{*}}^{t_{4}^{*}-Z \gamma^{*}} g(\varepsilon, \eta) d \varepsilon d \eta\right)+ \\
& \sum_{I N N O=1, I N N O_{-} S=5} \ln \left(\int_{-X \beta}^{\infty} \int_{t_{4}^{*}-Z \gamma^{*}}^{t_{5}^{*}-Z \gamma^{*}} g(\varepsilon, \eta) d \varepsilon d \eta\right)+ \\
& \sum_{I N N O=1, I N N O_{-} S=6} \ln \left(\int_{-X \beta}^{\infty} \int_{t_{5}^{*}-Z \gamma^{*}}^{\infty} g(\varepsilon, \eta) d \varepsilon d \eta\right)
\end{aligned}
$$

where the indices under the summation signs indicate the observations over which the sums are taken, $t_{i}^{*}=t_{i}^{\prime} / \sigma_{\eta}(\mathrm{i}=1, \ldots, 5)$ and $\gamma^{*}=\gamma / \sigma_{\eta}$.

For reasons of statistical confidentiality, we cannot pool the three countries' data. We therefore estimate the model separately for each country. The explanatory variables are industry group dummies and size (expressed in logarithms) for the probit equation. Remember that this is about all we know about non-innovators from the innovation surveys. For the ordered probit equation, dummies are constructed for the following: incidence of internal R\&D; firms with more than the median number of innovation activities; co-operation or collaboration with other firms, universities or government institutions; proximity to basic research; competitive pressure; 
novelty of innovation; and use of government support for innovation (see previous section). Each sample unit in each database is assigned a weight based on the number of sample units it represents in a given stratum for the population. This weight (the inverse of the sampling rate) is applied to each term in the log-likelihood function. In this way, inferences can be drawn about the whole population.

We then estimate the same kind of model for first-to-market innovators. The only difference with respect to the preceding model is in the selection equation. The equivalent of equation (1) selects first-to-market innovators from non-innovators or simple innovators, and the equivalent of equation (2) only holds for first-to-market innovators. The latent variables INNO* and ZINNO_S* are respectively replaced by INNOF* and ZINNOF_S*. By pooling non-innovators and simple innovators, we ignore some of the information we have about simple innovators. All we do is examine the likelihood of being a first-to-market innovator and the conditional intensity of innovation. Do first-to-market innovators differ from simple innovators in their characteristics and do the three countries differ in the determinants of both types of innovators?

Once the structure of innovation determinants are estimated for each country, we proceed to bilateral innovation comparisons. How much of the observed differences in innovation performance between Canada and respectively France and Germany can be attributed to differences in the underlying determinants of innovation?

From the estimated model parameters we can construct three measures of innovation, for simple innovators and first-to-market innovators respectively. The probability to innovate is given by

$$
E\left(I N N O^{*} \mid X\right)=\int_{-X \beta}^{\infty} f_{1}(\varepsilon) d \varepsilon
$$

The intensity of innovation for innovating firms is given by

$$
E\left(I N N O_{-} S \mid Z, I N N O^{*} \geq 0\right)=\int_{-\infty}^{\infty} \exp \left(Z \gamma+\sigma_{\eta} \eta\right) /\left(1+\exp \left(Z \gamma+\sigma_{\eta} \eta\right)\right) f_{2}(\eta) d \eta
$$

and the expected intensity of innovation for every firm in the sample, innovative or not, is given by the convolution of the previous two measures

$$
\begin{aligned}
& E\left(I N N O_{-} S \mid X, Z\right)= \\
& \int_{-X \beta}^{\infty} \int_{-\infty}^{\infty} \exp \left(Z \gamma+\sigma_{\eta} \eta\right) /\left(1+\exp \left(Z \gamma+\sigma_{\eta} \eta\right)\right) g(\varepsilon, \eta) d \varepsilon d \eta
\end{aligned}
$$


where $f_{1}(\varepsilon)$ and $f_{2}(\eta)$ are, respectively, the marginal normal distribution functions of $\varepsilon$ and $\eta$. It should be noted that (7) is the product of (5) and (6) when $\varepsilon$ and $\eta$ are independent. The conditional mean was evaluated at the estimated values of $\beta, \gamma, \rho$ and $\sigma_{\eta}$ using a GaussLegendre quadrature to compute the integrals.

To compare Canada with France, and Germany respectively, on these three measures, for each type of innovation, we linearly approximate each function around the Canadian averages for each variable. In other words, if we denote the function (5), (6) or (7) as $\mathrm{Y}=\mathrm{f}(\mathrm{X})$, and $\bar{Y}_{i}\left(\bar{X}_{i}\right)$ the sample average of variable $\mathrm{Y}(\mathrm{X})$ in country $\mathrm{i}$, the linear approximation states that

$$
\bar{Y}_{F}-\bar{Y}_{C}=\Gamma_{X \mid C}\left(\bar{X}_{F}-\bar{X}_{C}\right)
$$

where $\Gamma_{X \mid C}$ denotes the gradient of $\mathrm{Y}$ with respect to $\mathrm{X}$, evaluated at the average values for $\mathrm{C}, \mathrm{F}$ stands for France and $\mathrm{C}$ for Canada. A similar linear approximation is done for Germany.

\section{Results}

Table 2a presents the econometric estimates of the model described in the previous section using simple innovators as the innovation measure. Two specifications are presented for each country, one with and one without first-to-market innovation, patenting and their interaction. The specification with the three innovation output indicators allows to estimate whether firms that introduce products new to the firm also tend to introduce products new to the market or tend to patent, and whether there is complementarity between first-to-market innovation and patenting, in the sense that doing both gives an additional boost to simple product innovation. In France and in Canada, the two specifications yield very similar coefficients. In Germany, the estimates are more sensitive. The effect of internal R\&D is no longer significant, and the number of innovation activities, proximity to basic research and competition flip sign when we introduce the additional innovation indicators. As we shall see in table $3 \mathrm{a}$, the corresponding marginal effects are small. Nevertheless, the sign changes might reveal a simultaneity problem, as the introduction of products new to the market and patenting are themselves likely to be endogenous. Being a first-to-market innovator and patenting are both individually positively correlated with the intensity of simple innovation in France and Germany, but they seem to substitute for each other as the negative coefficient of the interaction variable suggests. This means that an enterprise that introduces a market-first innovation tends to have a higher share of innovative sales, the more so if it does not patent at the same time. An enterprise that patents tends to be more innovative, unless it introduces first-to-market innovations at the same time. In Canada, imitative and true innovations are not significantly correlated and patenting in itself is negatively correlated with simple innovations. Positive correlations only show up for firms that patent and are true innovators. In other words, in Canada there seems to be a complementarity between the three innovation outputs. 
In the three countries, the probability to be a simple innovator and the intensity of innovation increase with sectoral technological intensity. The incidence of simple-innovation is positively correlated with size in all three countries, but not necessarily the intensity. In Germany, the intensity of innovation decreases with firm size, whereas the Canadian and French data indicate a positive size effect. This finding is not out of line with those reported in previous studies. ${ }^{9}$ The four factors related to innovation activities (doing internal R\&D, multiple innovation activities, cooperating and receiving government support) contribute favourably to innovation, at least when they are significant, except for multiple innovation activities in Germany when other innovation indicators are controlled for. These findings corroborate the assumption that to be innovative (and to profit from innovation) firms must develop their innovation capability, and that such capability cannot be taken for granted. ${ }^{10}$ While most of the factors related to innovation capacity follow the same trend, the effects of environment variables differ by countries. Proximity to basic research is generally negatively correlated with the intensity of innovation although not significantly so in Canada. Hall, Link and Scott (2000) conclude from their analysis of partnerships in the U.S. Advanced Technology Program that industry approaches universities for projects that involve new science, unknown technological territory, hence more for knowledge acquisition than for projects that are profitable in the short term. ${ }^{11}$ Pressure from competition is positively correlated with innovation intensity, except in the case of Germany when other innovation output effects are not controlled for. This result confirms that, in general, competition is favourable to innovation.

Table $2 \mathrm{~b}$ presents the estimation results for first-to-market innovations. These estimates by and large confirm those of table 2a. First-to-market innovations are more frequent and lead to higher innovative sales in high-tech industries. Activities related to innovation and perceived competitive pressure are positively correlated with innovative sales for first-to-market innovators whereas proximity to basic research is still negatively correlated to it. The only exception is Germany, where the intensity of innovation is negatively correlated with multiple innovation activities and competitive pressure. In Canada, size of the firm, government support program, pressure from competition, and proximity to basic research are not significantly correlated with the intensity of innovation for first-to-market-innovators. The next tables will help to explain better the differential effects of the explanatory variables on the simple and the first-to-market innovation performances.

Table 3a reports the marginal effects of the main explanatory variables on the various modalities of innovation: the propensity not to innovate and the propensity to achieve given categorical percentages of innovative sales - less than $15 \%$, from $15 \%$ to $50 \%$, or more than $50 \%$. The sum of the marginal effects across the different possibilities (i.e., on each line) is equal to zero. The results have to be interpreted in the following way. The propensity to be (or not to be) a simple

\footnotetext{
${ }^{9}$ In Crépon, Duget and Mairesse (1998) and in Mairesse and Mohnen (2001), size was not significant, while in Lööf and Heshmati (2003) size was negatively correlated with innovation output (sales from innovation per employee).

${ }^{10}$ See Cohen and Levinthal (1989) and Oerlemans, Meeus and Boekema (1998) for a literature review of innovation capability.

11 University and public labs are also involved in applied research, which might result with innovations that are highly regarded by the market in the short run, as suggested by the positive coefficient of basic research in the first specification (without the innovation indicators) for Germany.
} 
innovator and to fall into one of the three sales categories of innovative behaviour are computed at the mean values of the explanatory variables - i.e., at the observed proportion of firms in the various industrial sectors, of firms carrying out internal $R \& D$, of firms receiving government support and so on. The marginal effects are the changes in those probabilities if a firm increases its size by $1 \%$, or shifts from one industry to another, or moves from non-collaboration to cooperation with other firms, etc. In other words, what is the additional likelihood of being in one of the four categories of innovation behaviour shown in Table $3 \mathrm{a}$ as the result of a change (ceteris paribus) in one selected variable? For example, when a French firm switched from a medium-tech to a high-tech industry, the following changes would occur: its propensity not to innovate would fall by $15 \%$ (from 0.69 to 0.54 ); its probability of being a low-intensive innovator (deriving less than $15 \%$ of sales from innovative products) would increase by $9 \%$ (from 0.04 to 0.13 ); its probability of being a medium-intensive innovator (sales from innovative products of between $15 \%$ and $50 \%$ ) would increase by $3 \%$ (from -0.37 to -0.34 ); and its propensity to be an intensive innovator (more than $50 \%$ of sales from innovative products) would increase by $2 \%$ (from -0.36 to -0.34 ). The same change in a German firm would result in a $1 \%$ higher probability of innovating, a $1 \%$ lesser chance of being a low-intensive innovator, a $1 \%$ lesser chance of being a medium-intensive innovator and a $2 \%$ greater chance of being an intensive innovator. In the same manner, a Canadian firm would result in a $8 \%$ higher probability of innovating, a $2 \%$ lower chance of being a low-intensive innovator, a $5 \%$ greater chance of being a medium-intensive innovator and a $5 \%$ greater chance of being an intensive innovator. The sensitivity of innovation intensity to a shift from a medium-tech to a high-tech industry is thus more acute in Canada than in Germany and in France.

Canadian firms are also more sensitive than French or German firms in their innovation output performance to innovation input factors: internal R\&D, the number of innovation activities and co-operation with other firms. Other innovation output realizations, however, influence innovation intensity more in France and Germany than in Canada. German firms are more sensitive to government support programs, and to the fact of being or not a first-to-market innovator. If we compare $3 \mathrm{a}$ and $3 \mathrm{~b}$, we notice that, except for size, all marginal effects are lower for first-to-market innovators than for simple innovators. Duguet (2002), Baldwin and Hanel (2003), and Landry and Amara (2003) report a lower importance or even irrelevance of competition and a greater influence of size and R\&D for the probability of being a first-tomarket innovators than a simple innovators. Therrien and Chang (2003) obtain a greater role of collaborations for first-to-market innovators than for simple innovators. The estimates are not exactly comparable. While we compute the marginal effects of selected variables on the intensity of innovation, these authors compute the marginal effects on the incidence of simple versus innovation first-to-market innovators. ${ }^{12}$ It also seems that the marginal effects are more similar across countries for first-to-market innovators than for simple innovators. For example, a one percent increase in the number of employees increases by about $9 \%$ to probability to be a firstto-market innovator, which in terms of innovative sales translates into a 3\% higher chance to produce from 0 to $15 \%$ of innovative sales, a $4 \%$ higher chance to innovate between $15 \%$ and $50 \%$ of total sales, and a $2 \%$ higher chance to produce more than $50 \%$ of innovative sales.

\footnotetext{
${ }^{12}$ We could not analyse the impact of variables other than size and industry composition on the incidence of innovation because the Canadian and CIS questionnaires are not structured in the same way.
} 
Tables $4 \mathrm{a}$ and $4 \mathrm{~b}$ present the results of the decomposition of the expected bilateral innovation performance comparison between Canada and France, and Canada and Germany, for simple innovators and first-to-market innovators respectively. As explained in the previous section, we base the comparison on linear expansions around Canadian means using gradients evaluated at Canadian estimates. The results do not differ much when we base the comparison on estimates obtained from the French or German samples. Similar stories across countries were also found by Mohnen and Dagenais (2002) for the case of Ireland and Denmark and by Janz et al. (2003) for the case of Germany and Sweden. ${ }^{13}$

Table 4a shows that firms in the Canadian sample are expected to have a greater probability of innovating (column 1) than German firms, but a lower intensity of innovation, be it for innovating firms or for all firms (columns 2 and 3). The same pattern arises for first-to-market innovators (columns 4, 5, and 6). The model allows the difference in expected innovation performance to be split into what is attributed to structural effects, such as differences in size, R\&D efforts and pressure of competition, and what, for lack of a better explanation, is attributed to innovativeness.

Estimates for innovators and first-to-market innovators reveal that the net effect of the industrial distribution (the sum of the three sectors in each column) favours Germany most of the time. The average firms' size -larger in Canada- is favorable to Canada as larger firms are more likely to innovate (and to be first-to-market innovators) as well as to have a larger share of sales from innovation. Moreover, the effect of size is more prevalent in the probability to be a first-tomarket innovator $(0.73 \%)$ than in the probability to be innovator $(0.46 \%)$. Co-operation with other firms, use of government support programs and proximity to basic research are more prominent in Canada than in Germany for innovators as well as for first-to-market innovators. Differences in the scope of innovation, measured by the number of innovation activities undertaken, in internal R\&D and in perceived competition give an advantage to Germany - that is, they are more prevalent in German than in Canadian firms for both innovation measures. Among the innovators, internal $\mathrm{R} \& \mathrm{D}$, multiple innovation activities and cooperation explain a greater part of the difference for first-to-market innovators than for simple innovators. The structural effects - i.e., of all the expected differences that can be attributed to explanatory variables - almost add up to the expected differences. The small discrepancy is due to the linear approximation error in the decomposition of a non-linear function.

Whatever difference in observed innovation performance is not explained by the model is what Mairesse and Mohnen (2001) call "innovativeness." Innovativeness in all three dimensions (the probability of innovating, and the intensity of innovation for innovators and for all firms) is thus measured as the difference in observed innovation unexplained by the structural effects in the model. Canadian firms have a greater unexplained tendency to innovate than German firms for simple innovations, but German firms have a higher unexplained intensity of innovation than Canadian firms. For first-to-market innovations, the combination of observed and structurally explained differences leaves unexplained the superiority of Germany in all regards. It is evident

\footnotetext{
${ }^{13}$ The estimates from each country mimic best the endogenous variables of that country. For instance, if we apply the Canadian estimates to the French data we predict innovation records that are closer to the Canadian levels than to the French levels. This does not, however, preclude that expected bilateral differences are insensitive to the particular estimates that are used.
} 
that our econometric model and list of explanatory variables explain only a small fraction of the observed differences in innovation performance. Mairesse and Mohnen (2001) reach the same conclusion, although the multilateral nature of their comparison provided more variation to be explained than our bilateral comparison.

Compared to France, Canada is expected to have a lower propensity to innovate, but a higher intensity of innovation for innovating firms (Table 4b). Putting the two effects together we would expect from our model that French firms innovate more. This holds for simple innovations. For first-to-market innovations, however, we would expect Canadian firms to outperform French firms in all respects. The sectoral composition of the manufacturing output favours France over Canada in both models and in each specification. Given comparative size, governmental support for innovation and the scope of innovation activities, we would expect Canadian firms to innovate more. Differential competition and R\&D efforts should make French firms innovate more. Other innovation output manifestations should also be more favourable to French innovative performance. For first-to-market innovators, we would expect from the frequency of collaborations more innovations in Canada compared to France. But the actual numbers show that Canadian firms have a pervasive superiority in innovation compared to French firms in all respects. Again, our model explains very little of the observed differences and therefore Canadian firms are more "innovative" than French firms. The differences are much smaller though for first-to-market innovators than for simple innovators.

\section{Conclusion}

The comparison of the innovation performance of manufacturing firms in Canada and France and Canada and Germany, on the basis of microdata information provided by the innovation surveys of the late 1990s, reveals that Canada had a 37 percentage points higher proportion of innovative firms than France, but only a 3 percentage points higher intensity of innovation, as measured by the share in total sales due to new or improved products. If newness is defined with respect to the market and not just with respect to the firm, the lead in the percentage of innovation-declaring firms drops to $3 \%$ and the share of first-to-market innovative sales moves up by $5 \%$. Compared to Germany, the percentage of simple innovators is 12 percentage points higher in Canada, but the intensity of innovation is 22 percentage points lower for Canadian innovating firms. When it comes to compare new-to-market innovators, Germany has more of them, and they are more innovative than the sampled Canadian firms. The econometric analysis attempts to explain part of this difference as the result of the sectoral composition of output, and the effects of size, environment conditions (proximity to basic research and competition) and innovation activities (internal R\&D, the number of innovation activities, cooperation and government support). The Canadian firms benefit from being larger and more numerous in receiving more government support, but suffer from a lack of competition and internal R\&D. These structural effects combined, while informative, were not enough to explain the basic pattern of innovation revealed by the raw data. If we take the stronger measure of first-to-market innovation as a yardstick of innovation, the observed pairwise country differences are less strong, and our model explains a little bit more of the observed differences.

Our model explains indeed disappointingly little of the bilateral observed differences in innovation records. In part the model needs some refinement to include certain aspects that are 
more commonly modeled in evolutionary theories of technological change, such as technological trajectories, network effects or national systems of innovation. In part, the dataset ought to be enlarged to include more explanatory variables by merging innovation surveys with other census or survey data covering the same firms. With the addition of new surveys, we might soon be able to adopt a panel data approach instead of a mere cross-section approach. In particular, we would then be able to model sluggishness and persistence in innovation realisations and correct for some of the endogeneity biases that might presentely affect our results. We also hope that as firms and statistical agencies learn to run these surveys that a more objective, unambiguous and homogeneous definition of innovation will be adopted. Finally, it would be useful to get an idea of the selection bias resulting from the mandatory versus voluntary nature of the surveys. 


\section{References}

Abramovsky, L., J. Jaumandreu, E. Kremp, and B. Peters, 2005, "National Differences in Innovation Behaviour: Facts and Explanations (France, Germany, Spain and the United Kingdom)”, mimeo.

Baldwin, J.R. and P. Hanel, 2003, Innovation and Knowledge Creation in an Open Economy. Cambridge: Cambridge University Press.

Brouwer, E. and A.H. Kleinknecht, 1996, "Determinants of Innovation. A Microeconometric Analysis of Three Alternative Innovation Output Indicators" in Kleinknecht, A. (ed.), Determinants of Innovation: The Message from New Indicators. London: Macmillan and New York: St. Martin's Press.

Cohen, W.M. and D.A. Levinthal, 1989, "Innovation and Learning: The Two Faces of R\&D," The Economic Journal, 99, 569-96.

Cozzarin, B., 2003, "World-First Innovation and Firm Performance", in Understanding Innovation in Canadian Industry, F. Gault (ed.), School of Policy Studies, Queen's University, Kingston and Montreal : McGill-Queen's University Press.

Crépon B., E. Duget and J. Mairesse, 1998, "Research, Innovation, and Productivity: An Econometric Analysis at the Firm Level," Economics of Innovation and New Technology, 7(2), $115-58$.

Duguet, E., 2002, "Innovation Height, Spillovers and TFP Growth at the Firm Level: Evidence from French Manufacturing”, Cahiers de la MSE, \#2002.73.

Foyn, F., 1999, “Community Innovation Survey 1997/1998,” Statistics in Focus, Eurostat, Theme 9, 2/1999.

Foyn, F., 2000, “Community Innovation Survey 1997/1998,” Statistics in Focus, Eurostat, Theme 9, 2/2000.

Griffiths, R., E. Huergo, J. Mairesse and B. Peters, 2005, "R\&D, Innovation and Productivity in Four European Countries (France, Germany, Spain and the United Kingdom)”, mimeo.

Guellec, D. and B. Pattinson, 2001, "Innovation Surveys: A Few Lessons from OECD Countries' Experience," STI Review: Special Issue on New Science and Technology Indicators, OECD, 27, 77-102.

Hall, B., A. Link and J. Scott, 2000, "Universities as research partners", NBER working paper 7643.

Hatzichronoglou, T., 1997, "Revision of the High-Technology Sector and Product Classification," STI Working Papers — 1997/2, OECD, Paris. 
Janz, N., H. Lööf and B. Peters, 2003, "Firm Level Innovation and Productivity - Is There a Common Story Across Countries”, ZEW Discussion Paper No. 03-26.

Landry, R. and N. Amara, 2003, "Effects of Sources of Information on Novelty of Innovation in Canadian Manufacturing Firms", in Understanding Innovation in Canadian Industry, F. Gault (ed.), School of Policy Studies, Queen's University, Kingston and Montreal : McGill-Queen's University Press.

Lööf, H. and A. Heshmati, 2003, "On the Relationship Between Innovation and Performance: A Sensitivity Analysis,” Economics of Innovation and New Technology (forthcoming).

Lööf, H., A. Heshmati, R. Asplund and S.-O. Nåås, 2003, "Innovation and Performance in Manufacturing Industries: A Comparison of the Nordic Countries", Journal of Management Research, forthcoming.

Mairesse, J. and P. Mohnen, 2001, "To Be or Not to Be Innovative: An Exercise in Measurement," STI Review: Special Issue on New Science and Technology Indicators, OECD, 27, 103-29.

Mohnen, P. and M. Dagenais, 2002, “Towards an Innovation Intensity Index: The Case of CIS-I in Denmark and Ireland," in Innovation and Firm Performance: Econometric Explorations of Survey Data (Alfred Kleinknecht and Pierre Mohnen, eds.). Palgrave, Hampshire and New York, 3-30.

Mohnen, P. and P. Therrien, 2003, "Comparing Innovation Performance for Canadian Firms and those from Selected European Countries: an Econometric Analysis", in Understanding Innovation in Canadian Industry, F. Gault (ed.), School of Policy Studies, Queen's University, Kingston and Montreal : McGill-Queen's University Press.

OECD/Eurostat, 1997, Oslo Manual: Proposed Guidelines for Collecting and Interpreting Technological Innovation Data, OECD/Eurostat, Paris.

Oerlemans, L.A.G., M.T.H. Meeus and F.W.M. Boekema, 1998, "Learning, Innovation and Proximity," ECIS Working Paper 98/3, Faculty of Technology Management, Eindhoven University of Technology, Eindhoven.

Schaan S. and B. Nemes, 2003, "Survey of Innovation 1999 - Methodological Framework: Decisions Taken and Lessons Learned in Understanding Innovation in Canadian Industry" in Understanding Innovation in Canadian Industry (Gault, Fred, ed), McGill-Queen's University Press, pages 17-31.

Therrien, P. and V. Chang, 2003, "Impact of Local Collaboration on Firms' Innovation Performance", in Understanding Innovation in Canadian Industry, F. Gault (ed.), School of Policy Studies, Queen's University, Kingston and Montreal : McGill-Queen's University Press. 
Therrien, P. and P. Mohnen, 2003, "How Innovative Are Canadian Firms Compared to Some

European Firms?: A Comparative Look at Innovation Surveys," Technovation, 23(4), 359-69. 


\begin{tabular}{|c|c|c|}
\hline \multirow[t]{2}{*}{ NAICS Code } & $\begin{array}{l}\text { NACE Code } \\
\text { (Rev. 1) }\end{array}$ & Corresponding Economic Activities \\
\hline & & Low-Tech \\
\hline $311-312$ & $15-16$ & Food, Beverage and Tobacco Products \\
\hline $313-316$ & $17-19$ & Textile Mills, Textile Product Mills, Clothing, Leather and Allied Products \\
\hline \multirow[t]{2}{*}{$321-322$} & $20-21$ & Wood Products and Paper \\
\hline & & Medium-Tech \\
\hline 324 & 23 & Petroleum and Coal Products \\
\hline $326-327$ & $25-26$ & Rubber and Other Nonmetallic Products \\
\hline $331-332$ & $27-28$ & Basic and Fabricated Metal Products \\
\hline 333 & 29 & Machinery and Equipment \\
\hline $3345-3346$ & 33 & Navigational, Medical, Medial and Optical Equipment \\
\hline $3361-3363$ & 34 & Motor Vehicles, Trailers and Semi-Trailers \\
\hline $337 \& 339$ & 36 & $\begin{array}{l}\text { Furniture and Related Products and Miscellaneous Manufacturing } \\
\text { High-Tech }\end{array}$ \\
\hline 325 & 24 & Chemicals and Chemical Products \\
\hline 3341 & 30 & Computers and Peripheral Equipment \\
\hline $3344 \& 335$ & 31 & Electrical and Electronic Machinery and Equipment \\
\hline $3342-3343$ & 32 & Radio, Television and Communications Equipment and Apparatus \\
\hline 3364-3369 & 35 & Aerospace Products and Parts, and Other Transportation Equipment \\
\hline
\end{tabular}




\begin{tabular}{|l|c|c|c|c|c|c|}
\hline \multicolumn{5}{|c|}{ Table 1. Descriptive statistics: weighted averages } \\
\hline & \multicolumn{2}{|c|}{ France } & \multicolumn{2}{c|}{ Germany } & \multicolumn{2}{c|}{ Canada } \\
\hline Variables & $\begin{array}{l}\text { Simple } \\
\text { innovators }\end{array}$ & $\begin{array}{l}\text { First-to- } \\
\text { market } \\
\text { innovators }\end{array}$ & $\begin{array}{l}\text { Simple } \\
\text { innovators }\end{array}$ & $\begin{array}{l}\text { First-to- } \\
\text { market } \\
\text { innovators }\end{array}$ & $\begin{array}{l}\text { Simple } \\
\text { innovators }\end{array}$ & $\begin{array}{l}\text { First-to- } \\
\text { market } \\
\text { innovators }\end{array}$ \\
\hline Number of firms & 8556 & 4500 & 21204 & 8574 & 5464 & 1765 \\
\hline percentages & $41.4 \%$ & $21.8 \%$ & $66.3 \%$ & $26.8 \%$ & $78.6 \%$ & $25.1 \%$ \\
\hline Intensity of innovation & & & & & & \\
\hline Share of innov. sales (1 to 6) & 2.91 & 3.12 & 4.31 & 4.51 & 3.22 & 3.35 \\
\hline Industrial sectors & & & & & & \\
\hline Low-tech & $27.4 \%$ & $22.9 \%$ & $22.9 \%$ & $20.8 \%$ & $31.4 \%$ & $24.8 \%$ \\
\hline Medium-tech & $53.8 \%$ & $57.8 \%$ & $64.5 \%$ & $65.6 \%$ & $55.2 \%$ & $58.1 \%$ \\
\hline High-tech & $18.8 \%$ & $19.4 \%$ & $12.5 \%$ & $13.6 \%$ & $13.4 \%$ & $17.0 \%$ \\
\hline Size & & & & & & \\
\hline Nb of employees (in log) & 4.46 & 4.57 & 4.44 & 4.68 & 4.55 & 4.77 \\
\hline Activities related to innovation & & & & & & \\
\hline Internal R\&D & $70.7 \%$ & $77.7 \%$ & $74.7 \%$ & $90.0 \%$ & $64.2 \%$ & $75.5 \%$ \\
\hline Multiple innovation activities & $41.3 \%$ & $49.6 \%$ & $72.2 \%$ & $85.4 \%$ & $51.6 \%$ & $65.7 \%$ \\
\hline Cooperation & $37.6 \%$ & $40.4 \%$ & $25.6 \%$ & $31.2 \%$ & $36.3 \%$ & $47.1 \%$ \\
\hline Government support & $19.7 \%$ & $20.1 \%$ & $21.3 \%$ & $22.4 \%$ & $63.5 \%$ & $74.9 \%$ \\
\hline Environment & & & & & & \\
\hline Proximity to basic research & $18.0 \%$ & $18.8 \%$ & $47.7 \%$ & $41.8 \%$ & $15.8 \%$ & $23.3 \%$ \\
\hline Competition & $63.7 \%$ & $68.9 \%$ & $40.4 \%$ & $46.5 \%$ & $44.7 \%$ & $48.9 \%$ \\
\hline
\end{tabular}

* Category 1 corresponds to a share of innovative sales $\leq 0.05$; category 2 to a share between 0.05 and $0.15 ; 3$ to a share between 0.15 and $0.25 ; 4$ to a share between 0.25 and $0.50 ; 5$ to a share between 0.50 and 0.75 ; and 6 to a share $>0.75$. 
Table 2a. Ordered probit on categorical data of the share of innovative sales for simpleinnovators, with correction for selectivity

\begin{tabular}{|c|c|c|c|c|c|c|}
\hline \multirow{2}{*}{ Explanatory variables } & \multicolumn{2}{|c|}{ France } & \multicolumn{2}{|c|}{ Germany } & \multicolumn{2}{|c|}{ Canada } \\
\hline & \multicolumn{6}{|c|}{ Probit on innovation } \\
\hline \multicolumn{7}{|l|}{ Industrial Sector } \\
\hline Low Tech & $-1.934^{\star \star}$ & $-1.938^{\star *}$ & $-0.902^{\star *}$ & $-0.898^{\star \star}$ & -0.058 & 0.010 \\
\hline Medium Tech & $-1.723^{\star *}$ & $-1.725^{\star \star}$ & $-0.631^{* *}$ & $-0.627^{\star \star}$ & $0.145^{\star \star}$ & $0.187^{\star \star}$ \\
\hline High Tech & $-1.364^{\star *}$ & $-1.369^{\star *}$ & $-0.593^{* *}$ & $-0.593^{\star *}$ & $0.483^{\star *}$ & $0.475^{\star \star}$ \\
\hline \multirow[t]{2}{*}{ Log of number of employees } & $0.369 * *$ & $0.370^{\star *}$ & $0.266^{\star \star}$ & $0.265^{\star}$ & $0.147^{\star \star}$ & $0.138^{\star *}$ \\
\hline & \multicolumn{6}{|c|}{ Ordered probit on shares of innovative sales for innovators } \\
\hline Industrial Sector & & & & & & \\
\hline Tech & $-6.640 * *$ & $-6.648^{\star *}$ & -0.054 & $-0.516^{\star *}$ & $-2.079 * *$ & $-2.118^{* *}$ \\
\hline Medium Tech & $-5.709 * \star$ & -5.7 & $0.268^{\star \star}$ & $-0.144^{\star \star}$ & $-1.990 * *$ & $-2.049 * *$ \\
\hline High Tech & $-5.411^{* *}$ & $-5.462^{\star *}$ & $0.381^{\star *}$ & -0.010 & $-1.802^{\star *}$ & $-1.788^{* *}$ \\
\hline Log of number of employees & $0.497^{* *}$ & $0.472^{\star \star}$ & $-0.151^{\star \star}$ & $-0.118^{\star \star}$ & $0.035^{\star \star}$ & $0.067^{\star *}$ \\
\hline \multicolumn{7}{|l|}{$\begin{array}{l}\text { Activities related to } \\
\text { innovation }\end{array}$} \\
\hline Internal $R \& D$ & $0.063^{\star *}$ & 0.015 & $0.091^{* *}$ & -0.005 & $0.259^{\star *}$ & $0.253^{* *}$ \\
\hline Multiple innov. Activities & $0.278^{\star \star}$ & $0.227^{\star \star}$ & 0.05 & $-0.015^{\star *}$ & $0.272^{\star \star}$ & $0.243^{\star *}$ \\
\hline ration & -0.021 & -0.017 & $0.103^{\star *}$ & $0.096 * \star$ & $0.149^{\star *}$ & $0.124^{\star *}$ \\
\hline Government support & $0.169 * *$ & $0.168^{\star \star}$ & $0.404^{* \star}$ & $0.101^{\star \star}$ & $0.063^{\star \star}$ & $0.060 * *$ \\
\hline \multicolumn{7}{|l|}{ Environment characteristics } \\
\hline $\begin{array}{l}\text { Proximity to basic } \\
\text { research }\end{array}$ & $-0.219 * *$ & $-0.223^{\star *}$ & $0.083^{\star *}$ & $-0.044^{* *}$ & -0.006 & -0.071 \\
\hline Competition & $0.221^{\star *}$ & $0.182^{\star *}$ & $-0.044^{\star \star}$ & $0.431^{\star \star}$ & $0.065^{\star \star}$ & $0.072^{\star *}$ \\
\hline \multicolumn{7}{|l|}{ Innovation indicators } \\
\hline First-to-market innovat. & - & $0.511^{\star *}$ & - & $0.623^{\star \star}$ & - & 0.010 \\
\hline Patenting & - & $0.311^{\star *}$ & - & $0.111^{\star *}$ & - & $-0.044^{*}$ \\
\hline Patenting and first-innov. & - & $-0.401^{\star *}$ & - & $-0.404^{\star \star}$ & - & $0.113^{\star \star}$ \\
\hline Sigma & $2.420 * *$ & 2.3 & $1.712^{\star *}$ & $1.762^{\star \star}$ & $1.283^{\star \star}$ & $1.274^{\star \star}$ \\
\hline Rho & $-0.881^{\star *}$ & $-0.875^{\star \star}$ & $-0.251^{\star \star}$ & $-0.442^{\star \star}$ & -0.397 & -0.248 \\
\hline Log-likelihooc & -27616.5 & -27551.2 & -54502.9 & -54323.8 & -12540.0 & -12534.7 \\
\hline $\mathrm{N}$ (weighted) & 20 & 68 & 31 & 976 & & \\
\hline $\mathrm{N}$ (unweighted) & 44 & & 15 & & & \\
\hline
\end{tabular}

Note: * significant at $5 \%$ level, ${ }^{* *}$ significant at $1 \%$ level

Sources: Canada: 1999 Survey of Innovation, Statistics Canada; EU: CIS 2, Eurostat. 
Table $2 b$. Ordered probit on categorical data on the share of innovative sales for first-tomarket innovators, with correction for selectivity

\begin{tabular}{|c|c|c|c|}
\hline \multirow[t]{2}{*}{ Explanatory variables } & France & Germany & Canada \\
\hline & \multicolumn{3}{|c|}{ Probit on being a first-to-market product innovator } \\
\hline \multicolumn{4}{|l|}{ Industrial Sector } \\
\hline Low Tech & $-2.296 * *$ & $-1.918 * *$ & $-2.015^{\star \star}$ \\
\hline Medium Tech & $-1.972 * *$ & $-1.715^{\star *}$ & $-1.690 * \star$ \\
\hline High Tech & $-1.811^{\star *}$ & $-1.712^{\star *}$ & $-1.512^{\star *}$ \\
\hline \multirow[t]{2}{*}{ Log of number of employees } & $0.299 * *$ & $0.262^{\star \star}$ & $0.241^{\star *}$ \\
\hline & \multicolumn{3}{|c|}{$\begin{array}{l}\text { Ordered probit on the share of innovative sales for first-to- } \\
\text { market innovators }\end{array}$} \\
\hline Industrial Sector & & & \\
\hline Low Tech & $-8.382^{* *}$ & $-4.415^{\star *}$ & $-1.955^{\star \star}$ \\
\hline Medium Tech & $-7.273^{\star *}$ & $-4.199 * *$ & $-1.836^{\star *}$ \\
\hline High Tech & $-7.112^{\star \star}$ & $-3.945^{\star \star}$ & $-1.505^{\star \star}$ \\
\hline Log of number of employees & $0.568 * *$ & $0.317^{\star *}$ & 0.039 \\
\hline \multicolumn{4}{|l|}{ Activities related to innovation } \\
\hline Internal $R \& D$ & $0.177^{\star \star}$ & $0.057^{* *}$ & $0.345^{\star *}$ \\
\hline Multiple innov. activities & $0.312^{\star \star}$ & $-0.263^{\star *}$ & $0.315^{\star \star}$ \\
\hline Cooperation & $0.055^{\star *}$ & $0.120 * *$ & $0.176^{\star \star}$ \\
\hline Government support & $0.095^{\star \star}$ & $0.424^{\star \star}$ & 0.023 \\
\hline \multicolumn{4}{|l|}{ Environment characteristics } \\
\hline Proximity to basic research & $-0.161^{* *}$ & $-0.037 * *$ & -0.069 \\
\hline Competition & $0.191^{\star \star}$ & $-0.052^{\star \star}$ & 0.013 \\
\hline Sigma & $2.757 * \star$ & $2.709 * *$ & $1.252^{\star \star}$ \\
\hline Rho & $-0.908 * \star$ & $-0.966^{\star *}$ & -0.001 \\
\hline Log-likelihood & -17994.9 & -30444.1 & -6649.7 \\
\hline $\mathrm{N}$ (weighted) & 20668 & 31976 & 5464 \\
\hline $\mathrm{N}$ (unweighted) & 4434 & 1534 & 4404 \\
\hline
\end{tabular}

Note: $*$ significant at $5 \%$ level, ${ }^{* *}$ significant at $1 \%$ level

Sources: Canada: 1999 Survey of Innovation, Statistics Canada; EU: CIS 2, Eurostat. 
Table 3a. Marginal effects of explanatory variables (in percentage points) on

\begin{tabular}{|c|c|c|c|c|c|c|c|c|c|c|c|c|}
\hline \multirow[b]{2}{*}{ Sector } & \multicolumn{3}{|c|}{$\begin{array}{c}\text { Propensity not to } \\
\text { be simple-innovator }\end{array}$} & \multicolumn{9}{|c|}{ Propensity to have sales from innovative products } \\
\hline & FRA & GER & CND & FRA & GER & CND & FRA & GER & CND & FRA & GER & CND \\
\hline Low Tech & 0.77 & 0.32 & -0.02 & 0.07 & -0.04 & 0.47 & -0.43 & -0.10 & -0.14 & -0.41 & -0.18 & -0.33 \\
\hline Medium Tech & 0.69 & 0.22 & -0.06 & 0.04 & -0.05 & 0.48 & -0.37 & -0.08 & -0.11 & -0.36 & -0.09 & -0.31 \\
\hline $\begin{array}{l}\text { High Tech } \\
\text { Size }\end{array}$ & 0.54 & 0.21 & -0.14 & 0.13 & -0.06 & 0.46 & -0.34 & -0.09 & -0.06 & -0 & -0.07 & -0.26 \\
\hline $\begin{array}{r}\log (n b . \text { empl) } \\
\text { Innov. activities }\end{array}$ & -0.15 & -0.09 & -0.04 & 0.08 & 0.04 & 0.00 & 0.04 & 0.05 & 0.02 & 0.03 & 0.01 & 0.01 \\
\hline$R \& D i$ & & & & 0.00 & 0.00 & -0.06 & 0.00 & 0.00 & 0.02 & 0.00 & 0.00 & 0.04 \\
\hline Multi-activities & & & & -0.03 & 0.00 & -0.05 & 0.01 & 0.00 & 0.02 & 0.01 & 0.00 & 0.04 \\
\hline Coope & & & & 0.00 & -0.01 & -0.03 & 0.00 & -0.01 & 0.01 & 0.00 & 0.02 & 0.02 \\
\hline $\begin{array}{r}\text { Gvt support } \\
\text { Environment }\end{array}$ & & & & -0.02 & -0.04 & -0.01 & 0.01 & -0.03 & 0.00 & 0.01 & 0.07 & 0.01 \\
\hline Basic & & & & 0.03 & -0.01 & 0.02 & -0.01 & -0.01 & 0.00 & -0.01 & 0.02 & -0.01 \\
\hline $\begin{array}{l}\text { Competition } \\
\text { Inn. Indicators }\end{array}$ & & & & -0.02 & 0.00 & -0.02 & 0.01 & 0.00 & 0.00 & 0.01 & -0.01 & 0.01 \\
\hline First innovators & & & & -0.06 & -0.06 & 0.00 & 0.03 & -0.04 & 0.00 & 0.03 & 0.10 & 0.00 \\
\hline Patenting & & & & -0.04 & -0.01 & 0.01 & 0.02 & -0.01 & 0.00 & 0.02 & 0.02 & -0.01 \\
\hline $\begin{array}{l}\text { First innov. and } \\
\text { patenting }\end{array}$ & & & & 0.05 & 0.04 & -0.03 & -0.02 & 0.03 & 0.01 & -0.02 & -0.07 & 0.02 \\
\hline
\end{tabular}

Table 3b. Marginal effects of explanatory variables (in percentage points) on

\begin{tabular}{|c|c|c|c|c|c|c|c|c|c|c|c|c|}
\hline & \multirow{2}{*}{\multicolumn{3}{|c|}{$\begin{array}{l}\text { Propensity not to } \\
\text { be first-to-market } \\
\text { innovator }\end{array}$}} & \multicolumn{9}{|c|}{ Propensity to have sales from innovative products } \\
\hline & & & & & less tha & in $15 \%$ & from & $15 \%$ to & $50 \%$ & more & e than 5 & $50 \%$ \\
\hline & FRA & GER & CND & FRA & GER & CND & FRA & GER & CND & FRA & GER & CND \\
\hline Sector & 0.74 & 0.67 & 0.67 & -0.08 & -0.05 & -0.05 & -0.34 & -0.24 & -0.37 & -0.32 & -0.38 & -0.25 \\
\hline Low Tech & 0.64 & 0.59 & 0.57 & -0.06 & -0.03 & -0.03 & -0.29 & -0.20 & -0.31 & -0.28 & -0.36 & -0.22 \\
\hline $\begin{array}{l}\text { Medium Tech } \\
\text { High Tech } \\
\text { Size }\end{array}$ & 0.59 & 0.59 & 0.51 & -0.03 & -0.04 & -0.04 & -0.28 & -0.21 & -0.28 & -0.27 & -0.34 & -0.19 \\
\hline $\begin{array}{l}\log (n b . \text { empl) } \\
\text { Innov. activities }\end{array}$ & -0.10 & -0.09 & -0.08 & 0.04 & 0.02 & 0.02 & 0.03 & 0.05 & 0.04 & 0.02 & 0.03 & 0.02 \\
\hline$R \& D$ internal & & & & -0.01 & 0.00 & -0.03 & 0.00 & 0.00 & 0.01 & 0.01 & 0.00 & 0.02 \\
\hline Multi-activities & & & & -0.02 & 0.01 & -0.02 & 0.01 & 0.01 & 0.00 & 0.01 & -0.02 & 0.02 \\
\hline Cooperation & & & & 0.00 & 0.00 & -0.01 & 0.00 & -0.01 & 0.00 & 0.00 & 0.01 & 0.01 \\
\hline $\begin{array}{l}\text { Gvt support } \\
\text { Environment }\end{array}$ & & & & -0.01 & -0.02 & 0.00 & 0.00 & -0.02 & 0.00 & 0.00 & 0.04 & 0.00 \\
\hline Basic & & & & 0.01 & 0.00 & 0.01 & 0.00 & 0.00 & 0.00 & -0.01 & 0.00 & 0.00 \\
\hline Competition & & & & -0.01 & 0.00 & 0.00 & 0.01 & 0.00 & 0.00 & 0.01 & 0.00 & 0.00 \\
\hline
\end{tabular}


Table 4a. Comparison between Germany and Canada of the expected probability to innovate, intensity of innovation for innovators, and intensity of innovation for all firms (using Canadian estimates)




Table 4b. Comparison between France and Canada of the expected probability to innovate, intensity of innovation for innovators, and intensity of innovation for all firms (using Canadian estimates)

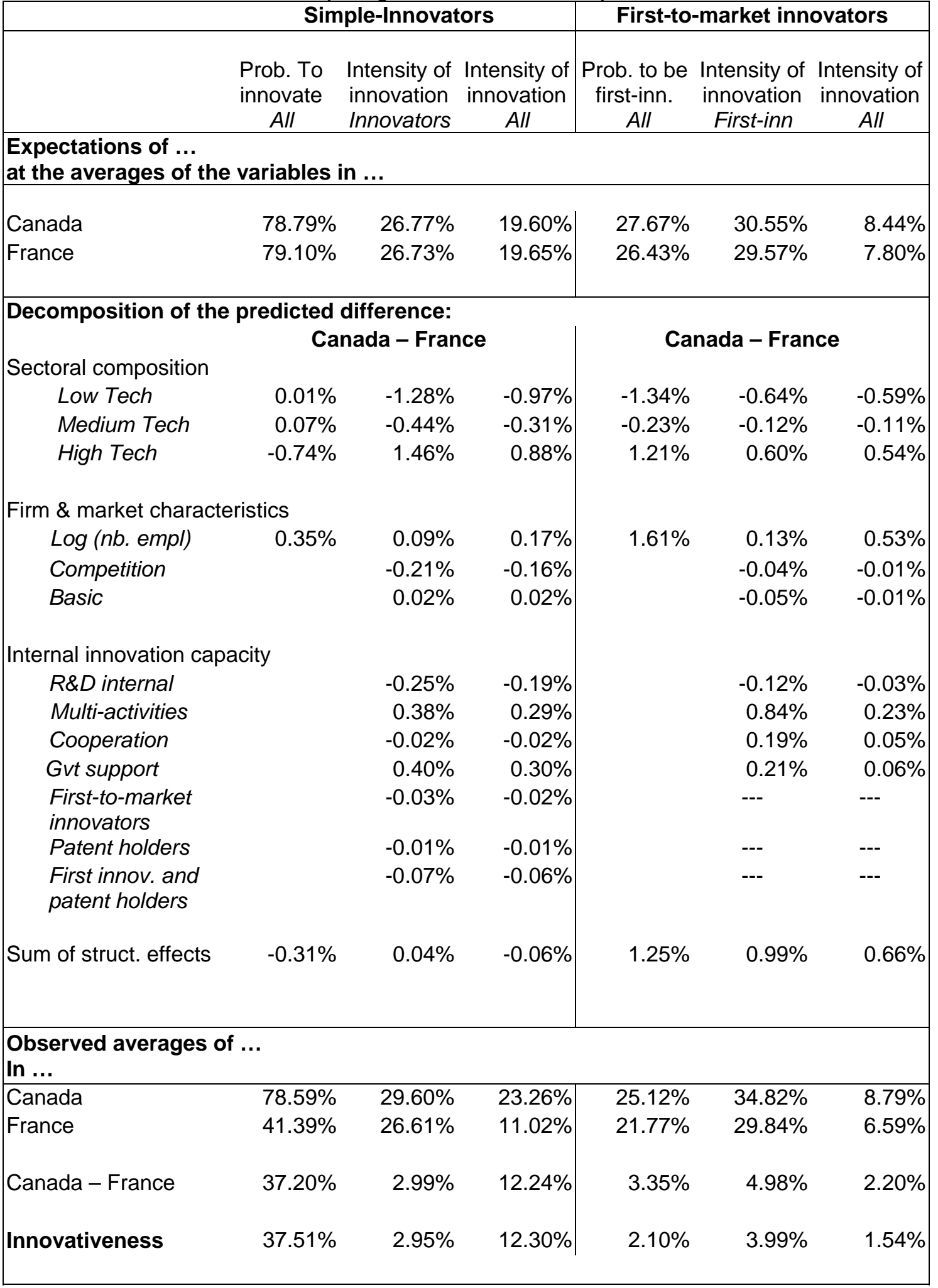

